\title{
Knowledge of Pressure Ulcer Management among Nurses
}

\author{
Shrestha $\mathbf{N}^{1 *}$, Shrestha $\mathbf{P}^{2}$ \\ 'Lecturer, Department of Nursing, ${ }^{2} \mathrm{RN}$ \\ Gandaki Medical College \& Teaching Hospital, Pokhara, Nepal
}

\author{
Keywords \\ Knowledge, Pressure ulcer management, \\ Nurses.

\section{Corresponding author \\ *Nisha Shrestha \\ Lecturer, Department of Nursing \\ Gandaki Medical College, Pokhara, Nepal \\ Email: nishapkr061@hotmail.com}

\begin{abstract}
Background: Pressure ulcer (PU) development remains a significant complication among at-risk patients. It is considered "never events" because they are preventable and should "never" happen. It has been associated with increased morbidity, mortality, hospital cost and length of stay in the hospital. Prevention of pressure ulcers is considered a nurse-sensitive indicator hence nurses should have adequate knowledge about current evidence-based prevention and management of pressure ulcer. However, non adherence to these guidelines is frequent and lack of knowledge may act as barriers to using guidelines in clinical practice.
\end{abstract}

Objectives: The objectives of the study were to 1 . assess the knowledge of pressure ulcer management among nurses 2 . determine the level of knowledge of pressure ulcer management among nurses 3 . assess the association of knowledge of nurses and baseline variables.

Methods: A descriptive cross sectional study was conducted, using pretested self administered questionnaire to assess the knowledge on pressure ulcer management among purposively selected 100 nurses working in Gandaki Medical College Teaching Hospital in 2015. Descriptive statistics as frequency and percentage were used and inferential statistics (Chi-square test) was done to find out association between knowledge and selected baseline variables.

Results: The study revealed that $59 \%$ of the respondents had adequate knowledge where as $41 \%$ of nurse's knowledge was found to be inadequate. Significant association was not found between age, working ward, experience, education, training, duration and knowledge of pressure ulcer management among Nurses.

Conclusion: This result indicates that more than half of the nurses had the adequate knowledge but there is still need of education and training related pressure ulcer management.

\section{INTRODUCTION:}

Pressure ulcer (PU) remains a significant problem in the healthcare system. In addition to the suffering it causes to patients, it also bears a growing financial burden, human suffering, pain, disfigurement, loss of productive time ${ }^{1,2}$. Pressure ulcers increase patient morbidity and mortality.
Stage IV pressure ulcers have a high cost, and stopping the progression of early stage pressure ulcers can decrease unnecessary pain impacting thousands of patient lives ${ }^{3}$.

Despite the fact that pressure ulcers are largely preventable and recent advances in health care sector, pressure ulcer rates are significantly increased in health 
care facilities ${ }^{4}$. Studies conducted in Europe, the United States, Canada and Australia provided estimates of pressure ulcer prevalence in hospitals ranging from $8.3 \%$ to $25.1 \%{ }^{5-8}$. In Nepal, the incidence and prevalence data regarding pressure ulcer were not available.

The presence or absence of pressure ulcers has been generally regarded as a performance measure of quality nursing care. Nurse, as a primary care giver should have the knowledge on pressure ulcer in order to carry out intervention necessary for prevention and management of complication of pressure ulcer ${ }^{9}$.

Knowledge increases nurses' awareness of problems of pressure ulcer and provides the basis for informed decision making and framework to develop and maintain competency of delivering high quality of nursing care ${ }^{10,11}$. Pressure ulcer prevention is the responsibility of all health care professionals who are involved in patient care ${ }^{12}$. Nursing research is invaluable and an integral part of nursing care, which aids in shaping and delivering quality care regarding prevention and treatment of pressure sores $^{13}$.

\section{OBJECTIVES}

The objectives of the study were to

1. Assess the knowledge of pressure ulcer management among nurses

2. Determine level of knowledge of pressure ulcer management among nurses

3. Assess the association of knowledge of pressure ulcer management among nurses and baseline variables.

\section{METHODS}

This study was carried out on 100 nurses working in different wards of Gandaki Medical College and Teaching Hospital, using purposive sampling technique. Pretested self administered questionnaire was used to collect data to assess knowledge of pressure ulcer management. The collected data was analyzed using descriptive and inferential statistics in SPSS 16 version. Descriptive statistics (frequency, percentage, mean and standard deviation) was used to describe baseline variables and knowledge of pressure ulcer management. Inferential statistics (chi-square) were used to show association between knowledge of pressure ulcer management among nurses and independent variables. Analyzed data was presented in tables, graphs and figures.

\section{RESULTS}

Fig 1: Distribution of respondents based on age $(n=100)$

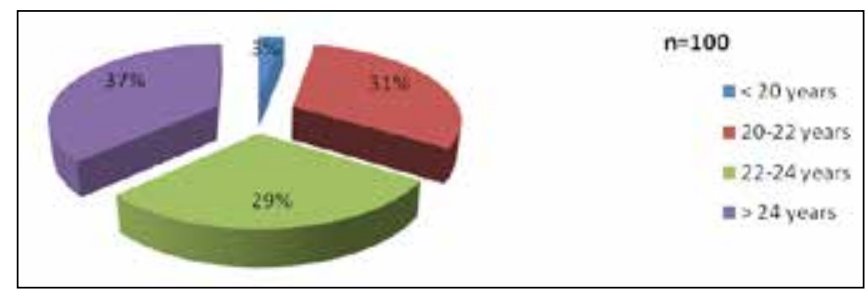

Fig 1 reveals that majority (37\%) of respondents were of age more than 24 years, $31 \%$ of respondents were of age 22 - 24 years followed by $29 \%$ of age $20-22$ years and least $(3 \%)$ were of age less than 20 years.

Table 1: Baseline data of respondents $(n=100)$

\begin{tabular}{lcc}
\hline \multicolumn{1}{c}{$\begin{array}{c}\text { Baseline Data } \\
\text { Experience (in years) }\end{array}$} & Frequency & Percentage \\
\hline$<1$ & 9 & 9 \\
$1-3$ & 71 & 71 \\
$3-5$ & 6 & 6 \\
$>5$ & 14 & 14 \\
Education & & \\
$\quad$ PCL Nursing & 92 & 92 \\
$\quad$ Bachelor in Nursing & 8 & 8 \\
Training & & \\
$\quad$ Yes & 7 & 7 \\
$\quad$ No & 93 & 93 \\
Duration (n=7) & & \\
$\quad$ One day & 5 & 71.4 \\
Two days & 2 & 28.6 \\
\hline
\end{tabular}

Table 1 shows that more than half (71\%) of respondents had experience of 1 - 3 years and least (9\%) of respondents had less than one year experience. Majority of respondents (92\%) had education of PCL nursing and only $8 \%$ had bachelor in nursing. Majority of respondents (93\%) had no formal training on pressure ulcer management and only $7 \%$ had formal training out of which most (71.4\%) had one day training and few (28.6\%) had two days training.

Table 2: Respondents' knowledge on Pressure ulcer $(n=100)$

\begin{tabular}{lll}
\hline & Frequency & Percentage \\
\hline Site of occurrence & 97 & 97 \\
Cause & 100 & $100 \%$ \\
Risk factor & 92 & $92 \%$ \\
Complication & 71 & $71 \%$ \\
\hline
\end{tabular}


Majority (97\%) of the respondents responded bony sites for occurrence of pressure ulcer. All the respondents $(100 \%)$ answered friction as a cause and majority (92\%) correctly identified risk factor of pressure ulcer whereas $71 \%$ identified complication of pressure ulcer (Table 2).

Table 3: Respondents knowledge on prevention of pressure ulcer $(\mathrm{n}=100)$

\begin{tabular}{llcc}
\hline S. No & Variables & Frequency & Percentage \\
\hline 1 & $\begin{array}{l}\text { Assessing for risk factors on } \\
\text { admission and routinely }\end{array}$ & 78 & $78 \%$ \\
2 & $\begin{array}{l}\text { Two hourly position } \\
\text { changing }\end{array}$ & 86 & $86 \%$ \\
3 & Positioning of patients & 58 & $58 \%$ \\
4 & Use of comfort devices & 44 & $44 \%$ \\
\hline
\end{tabular}

Most of respondents (78\%) responded to assess for risk factors of pressure ulcer on admission and routinely. Majority of respondents (86\%) correctly answered changing position every two hourly of bedridden patients; $58 \%$ answered correct positioning for relieving pressure and $44 \%$ of respondents answered use of comfort devices for prevention of pressure ulcer (Table 3).

Table 4: Respondents' knowledge on management of pressure ulcer $(\mathrm{n}=100)$

\begin{tabular}{lcc}
\hline Variables & Frequency & Percentage \\
\hline *Patient has discoloration of skin & & \\
Avoiding shearing force & 46 & $46 \%$ \\
Let next nurse know about it & 41 & $41 \%$ \\
$\begin{array}{l}\text { Place patient on pressure } \\
\text { reducing surface }\end{array}$ & 69 & $69 \%$ \\
$\begin{array}{l}\text { Notify physician } \\
\text { Protein rich diet }\end{array}$ & 46 & $46 \%$ \\
Dressing technique & 95 & $95 \%$ \\
Drug for managing pain & 44 & $44 \%$ \\
\hline
\end{tabular}

${ }^{*}$ Multiple response

When patient has discoloration of skin, most of the respondents (69\%) responded placing patient on pressure reducing surface, followed by $46 \%$ answered avoiding shearing force, $46 \%$ responded to notify physician and least $41 \%$ answered to let next nurse know about it. Majority (95\%) of respondents correctly answered to advice for protein diet, and nearly half of the respondents (44\%) correctly answered proper dressing technique. Likewise for managing pain $46 \%$ of respondents answered acetaminophen as drug of choice for managing pain (Table 4).

Table 5: Respondent's level of knowledge on pressure ulcer management $(\mathrm{n}=100)$

\begin{tabular}{lcc}
\hline Knowledge level & Frequency & Percentage \\
\hline Inadequate $(<$ mean) & 41 & $41 \%$ \\
Adequate $(\geq$ mean) & 59 & $59 \%$ \\
\hline
\end{tabular}

Mean 12.99

Almost half of the nurses (59\%) of respondents have an adequate knowledge of pressure ulcer management and $41 \%$ had inadequate knowledge (Table 5).

Table 6: Association between independent variables and knowledge of respondents $(n=100)$

\begin{tabular}{lcc}
\hline Independent variables & df & P-value \\
\hline Age & 3 & .050 \\
Working ward & 11 & .207 \\
Experience & 3 & .243 \\
Education & 1 & .167 \\
Training & 1 & .951 \\
Duration & 1 & .47 \\
\hline
\end{tabular}

Table 6 shows that there is no significant association between level of knowledge of respondents and independent variables like age, working ward, experience, education, training and duration of training.

\section{DISCUSSION}

Majority (37\%) of respondents were of age more than 24 years, 31\% of respondents were of age $22-24$ years followed by $29 \%$ of age 20 - 22 years and least (3\%) were of age less than 20 years. This indicates that most of the nurses were in the early age of their career. More than half $(71 \%)$ of respondents had experience of one to three years and least (9\%) had less than one year experience. This is a clear indication that respondents were not novices in nursing profession. These findings contrast with the study done on 87 nurses of Eric Williams Medical Sciences Complex where majority (86.7\%) of the respondents were 39 years or younger, with $73 \%$ of them having had only three years of experience or less ${ }^{14}$.

Findings also showed $41 \%$ of respondents have an inadequate knowledge of pressure ulcer management. 
This is less than the study done on 248 nurses of Gondar University Hospital in North West Ethiopia, where almost half $(45.5 \%)$ had inadequate knowledge ${ }^{15}$. Similarly, study done in Ethiopia found $61.2 \%$, in Jordan where $73 \%$ had inadequate knowledge ${ }^{1}$. The overall low level of knowledge may not be unconnected to their formal educational background and training experience. This study found that majority of respondents (92\%) had PCL in nursing and only $8 \%$ had bachelor in nursing. This limited formal educational qualification and training is a strong factor related to nurses' low level of knowledge. In addition, majority (93\%) of respondents had no formal training and only seven percent had formal training. The lack of opportunity to be trained and get updated on pressure ulcer prevention programs might be the reasons for low level of knowledge regarding pressure ulcer prevention. These findings are similar to previous study in which lack of training in pressure ulcer prevention care in Irish nurses was one of barrier to nurses accessing updated information about pressure ulcer prevention.

The findings of the study showed that there is no significant association between level of knowledge of respondents and independent variables like age, working ward, experience, education, training and duration of training. The findings are similar to the study where results revealed that nurses' knowledge had no relation with nurses' education, age, or years of work experience ${ }^{1}$. The findings contrast with the findings of the study done in Nigeria where significant relationship was found between nurses' work experience and knowledge ${ }^{6}$.

\section{CONCLUSION}

The major conclusion was drawn on the basis of objectives and study findings. The mean score of correct answer on the knowledge of nurses' result showed that $59 \%$ of nurses' knowledge was adequate. However $41 \%$ of nurses' knowledge was found to be inadequate which reveals that there is a need of education and training related pressure ulcer management.

\section{REFERENCES}

1. Qaddumi J, Khawaldeh A. Pressure ulcer prevention knowledge among Jordanian nurses: A cross sectional study. BMC Nursing. 2014; 13(6): 14726955. [internet] [cited 2015 Sep 30] Available from: http://bmcnurs.biomedcentral.com/articles/ 10.1186/1472-6955-13-6.
2. Abdel Rahman MS, Abdel Rahman RF, Al Assaf RM, Saleh MYN. Exploring nurses' knowledge and perceived barriers to carry out pressure ulcer prevention and treatment, documentation, and risk assessment. American International Journal of Contemporary Research. 2014 Apr; 4(4): 112-9.

3. Albert M, Lewis L. Knowledge and views about prevention and management of pressure ulcer. Asian academic research journal of multidisciplinary. 2014; 1: 231-9.

4. Saleh MYN, Saleh JM. Interventional study on effects of pressure ulcer education on Jordanian nurses knowledge. Social and behavioral sciences. 2012; 47: 2196-2206.

5. Hulsenboom MA, Bours GJW, Halfens RJG. Knowledge of pressure ulcer prevention: A cross sectional and comparative study among nurses. Biomedical Research. 2007; 6: 214-9.

6. Uba M.N et al. Knowledge, attitude and practice of nurses towards pressure ulcer prevention in University of Maiduguri Teaching Hospital, Borno state, North-Eastern, Nigeria. International Journal of Nursing and Midwifery. 2015; 7(4): 54-60.

7. Islam S. Knowledge, attitude and practice regarding pressure ulcer prevention for hospitalized patients at Rajshahi Medical College Hospital in Bangladesh. Prince of Songkla University. 2010;49-68 [internet] [cited 2016 Aug 25] Available from : http://kb.psu. ac.th/psukb/bitstream/2010/7830/1/326010.pdf.

8. Nurhusien N. Knowledge of nurses towards prevention of pressure ulcer and associated factors. BMC biocentral articles. 2015; 18: 2338-3734. [internet] [cited 2016 Feb 12 ] Available from: http:// bmcnurs.biomedcentral.com/articles/ 10.1186/ s12912-015-0076-8.

9. Mwebaza I Katende G, Groves S, Nankumbi J. Nurses' knowledge, practices, and barriers in care of patients with pressure ulcers in a Ugandan Teaching Hospital. Nursing Research and Practice. 2014; 7: 602-5.

10. Miyazaki Margareth Yuri, Caliri Maria Helena Larcher, Santos Claudia Benedita dos. Knowledge on pressure ulcer prevention among nursing professionals. Rev. Latino-Am. Enfermagem [Internet]. 2010 Dec [cited 2016 Nov10];18(6): 1203-1211. Available from: http://www.scielo.br/scielo.php?script=sci_arttext\& pid=S0104-11692010000600022\&lng=en.http:// dx.doi.org/10.1590/S0104-11692010000600022. 
11. Ayello E. Replication a survey of pressure ulcer context in nursing textbook. Journal of Wound Ostomy Continence Nursing. 2003; 266-71.

12. Beeckman D, Defloor T, Schoonhoven L, Vanderwee K. Knowledge of nurses on pressure ulcer prevention. Worldviews Evid Based Nurs. 2011 Sep; 8(3): 166-76.

13. Karen L. Cooper. Evidence-based prevention of pressure ulcers in intensive care unit. Critical care nurse. 2013; 33(6): 57-67.

14. Onuoha PC. Albert M, Campbell-George L, LewisL, Montrichard J, Polo-Williams N, Thom S. Knowledge and views about prevention and management of pressure ulcer: A case study of nurses at a Caribbean Teaching Hospital. Asian Academic Research Journal of Multidisciplinary. 2014 Apr; 1(20): 2319 - 2801. [internet] [cited 2016 Jan 3] Available from: http:// www.asianacademicresearch.org/2014_abstract/ april_md_2014/37.pdf

15. Nuru $\mathrm{N}$ et al. Knowledge and practice of nurses towards prevention of pressure ulcer and associated factors in Gondar University Hospital, Northwest Ethiopia. BMC Nursing. 2015; 14(34). 